\title{
Rodovias Inteligentes: uma visão geral sobre as tecnologias empregadas no Brasil e no mundo
}

\section{Title: Smart Roads: an overview of the technologies in Brazil and in the world}

\author{
Luciana Regina Bencke ${ }^{1}$, Anderson Luiz Fernandes Perez ${ }^{1}$, Osvaldo da Costa \\ Armendaris $^{2}$ \\ ${ }^{1}$ Programa de Pós-Graduação em Tecnologias da Informação e Comunicação \\ Universidade Federal de Santa Catarina (UFSC) \\ CEP 88.905-120 - Araranguá - SC - Brasil \\ 2 Departamento Nacional de Infraestrutura de Transportes (DNIT) \\ Superintendência Regional de Santa Catarina \\ CEP 88.020-180 - Florianópolis - SC - Brasil \\ luciana.bencke@gmail.com, anderson.perez@ufsc.br, \\ osvaldo.armendaris@dnit.gov.br
}

\begin{abstract}
The search for transforming highways into interactive and safe spaces, with sustainable and user-oriented solutions, gains more importance every day. Several international, public and private organizations are engaged in research projects and are part of the race for innovation in the field. In this context, Intelligent Transportation Systems play a fundamental role. Today there is a wide range of research related to those systems including technologies such as VANETs, systems based on information collected by sensors in vehicles and on smartphones and UAVS. This work presents a review of the topic Smart Roads and an analysis on the technologies used all over the world and in Brazil as well as the main challenges of information systems applied to highways. Huge transformations are coming on the international scene, but for Brazil, there are still many infrastructure problems to solve. Looking for high-value-added research and solutions should be an inspiration to develop systems that help the highways managers in the next steps towards the Smart Roads.
\end{abstract}

Keywords. Smart Roads; Intelligent Transportation Systems; ITS; Mobile Sensing; Wireless Sensor Network; Unmanned Aerial Vehicle; UAV.

Resumo. A busca por transformar as Rodovias em espaços interativos, seguros, com soluções sustentáveis e orientadas ao usuário da via, ganha mais importância a cada dia. Várias organizações internacionais, públicas e privadas se empenham nos projetos de pesquisa e na corrida pela inovação na área. Neste contexto, os Sistemas Inteligentes de Transporte desempenham papel fundamental. Atualmente existe um vasto leque de pesquisas

Cite as: $\quad$ Bencke, L. R., Perez, A. L. F., \& Armendaris, O. C. (2017). Rodovias Inteligentes: uma visão geral sobre as tecnologias empregadas no Brasil e no mundo (Smart Roads: an overview of the technologies in Brazil and in the world). iSys: Revista Brasileira de Sistemas de Informação (Brazilian Journal of Information Systems), 10(4), 80-102. 
relacionadas a estes sistemas englobando tecnologias como as VANETs, sistemas baseados em informações coletadas por sensores existentes nos veículos e nos smartphones e os VANTs. Este artigo traz uma revisão do tema Rodovias Inteligentes, apresentando uma análise sobre as tecnologias empregadas no Brasil e no mundo, bem como os principais desafios dos sistemas de informação aplicados às rodovias. Grandes transformações estão por vir no cenário internacional, mas no Brasil ainda existem muitos problemas de infraestrutura a resolver. Buscar por pesquisas e soluções de alto valor agregado deve ser inspiração para o desenvolvimento de sistemas que auxiliem os gestores das rodovias brasileiras nos próximos passos em direção às Rodovias Inteligentes.

Palavras-Chave. Rodovias Inteligentes; Sistemas Inteligentes de Transportes; ITS; Mobile Sensing; Rede de sensores sem fio; VANT.

\section{Introdução}

As rodovias têm um papel fundamental na sociedade, pois permitem a movimentação de mercadorias e pessoas, interligando as cidades, possibilitando acesso ao trabalho e à vários serviços como saúde e educação, conectando regiões e culturas e estimulando o desenvolvimento econômico e social. Segundo [Senna, 2014], rodovias abrem oportunidades para os mercados e contribuem na geração de empregos, trazendo benefício para comércio e trabalhadores locais. Mudanças na infraestrutura afetam os custos das viagens e desta forma influenciam o comportamento de produtores e consumidores.

No Brasil, o modal rodoviário foi priorizado em detrimento de outros modais através de planos nacionais como o Plano Geral Nacional de Viação, de 1934, e o Plano Rodoviário Nacional, de 1944, os quais representaram guias gerais para as entidades estaduais elaborarem outros planos que permitiam a definição das rodovias estaduais a partir das federais e das conexões entre os sistemas federal e estaduais, [Pereira, 2015]. A situação das rodovias brasileiras está muito aquém das existentes em países desenvolvidos, [Pereira, 2015] destaca que o Brasil possui um dos maiores índices de transporte de carga por rodovias do mundo, com um agravante: o baixo estado de conservação da malha pavimentada.

O DNIT (Departamento Nacional de Infraestrutura Terrestre), conceitua conservação e manutenção em seu glossário de termos técnicos rodoviários como:

"CONSERVAÇÃO 1) Conjunto de operações destinadas a preservar as características técnicas e operacionais de uma rodovia ou obra de arte de acordo com sua concepção original. 2) Conjunto de trabalhos necessários para que uma via ou obra de arte mantenha-se em boas condições de serviço. MANUTENÇÃO: Qualquer ação que mantém a rodovia em condições satisfatórias de operação. Pode ser preventiva ou corretiva. De maneira geral, Manutenção Rodoviária se dá com a utilização de vários tipos de intervenções ou por intermédio de programas de manutenção. [DNITc, 2017] 
A principal motivação deste trabalho é a necessidade de uma revisão de pesquisas relacionadas ao tema Rodovias Inteligentes de forma a embasar estudos e o desenvolvimento de sistemas de informação que auxiliem na gestão das rodovias brasileiras, sendo importante, portanto, a investigação do estado da arte, base para os próximos passos. O objetivo é apresentar uma visão geral inspirada em conceitos formulados por organizações comprometidas com o assunto, além de apresentar uma seleção de pesquisas, tendências e desafios no contexto global e brasileiro, abordando sistemas de informação para rodovias.

Para tanto foi realizada uma busca exploratória, com combinações das expressões "Rodovias Inteligentes", "Rede de sensores sem fio", "Veículos", "Infraestrutura", "Sistema de Transportes Inteligente", "Sistemas de Informação" e suas respectivas traduções em inglês, nas bases IEEE, Scopus, Springer e nas publicações de eventos relacionados ao tema. Considerou-se como relevante sobretudo o foco na aplicação das TICs (Tecnologias da Informação e Comunicação) em rodovias nos assuntos: rede de sensores sem fio, dados coletados por sensores nos veículos e nos smartphones, e Veículos Aéreos Não Tripulados (VANT). Foram também consultadas publicações relacionadas ao tema no USDOT (United States Department of Transportation), na Comissão Europeia e no DNIT (Departamento Nacional de Infraestrutura de Transportes).

A Seção 2 contém os conceitos de rodovia inteligente. A seguir, na Seção 3, são apresentadas pesquisas relacionadas a Sistemas Inteligentes de Transporte e conceitos da tecnologia empregada, com foco em 3 temas: rede de sensores sem fio, dados coletados por sensores nos veículos e smartphones, e VANT. Na Seção 4, é contextualizada a situação do sistema viário brasileiro; na Seção 5 são abordados os principais desafios na implementação de Sistemas Inteligentes de Transportes para as rodovias; e, por fim, na Seção 6 as considerações finais.

\section{Fundamentos de Rodovias Inteligentes}

Atualmente, a expressão "dispositivos inteligentes" remete às várias possibilidades de conexão a outros dispositivos e ao funcionamento interativo e, até certo ponto, autônomo. Essa ideia pode ser adotada também nas rodovias inteligentes, aliada a uma motivação social e econômica profunda: segurança, sustentabilidade e satisfação do usuário.

Em [USDOTa, 2017], destaca-se a importância de sistemas inteligentes nas rodovias pelo fato de melhorarem a segurança, a mobilidade e aumentarem a produtividade americana através da integração de tecnologias de comunicação avançadas com veículos e com infraestrutura. A Administração Federal de Rodovias (FHWA - Federal Highways Administration) é uma agência do USDOT que apoia os governos estaduais e locais no projeto, construção e manutenção do sistema rodoviário dos EUA. Para a FHWA, uma abordagem sustentável para as rodovias significa ajudar os tomadores de decisão a fazer escolhas equilibradas entre os valores ambientais, econômicos e sociais - o tripé da sustentabilidade - o que beneficia os usuários atuais e futuros da rodovia. Segundo [USDOTb, 2017], uma abordagem sustentável analisa o acesso (não apenas a mobilidade), o movimento de pessoas e bens (não apenas veículos) 
e a provisão de escolhas de transporte, como rotas seguras e confortáveis para caminhadas, ciclismo e trânsito.

A Comissão Europeia aborda questões relacionadas ao tema Rodovias Inteligentes em [EC, 2011], onde estabelece prioridades relacionadas a todos os modos de transporte. Em [EC, 2017] a Comissão destaca como temas da estratégia de transporte rodoviário da União Europeia (UE) os quatro tópicos:

- Mercado interno funcionando bem: regras claras e uma rede de transporte rodoviário mais eficiente em termos de custos tornará as empresas da UE mais competitivas a nível mundial, o que promoverá a criação de empregos. As tecnologias digitais vão facilitar a implementação destas novas regras.

- Concorrência justa e direitos dos trabalhadores: simplificar as regras e melhorar a cooperação entre os Estados-Membros para garantir condições de trabalho adequadas para os trabalhadores dos transportes e condições comerciais justas para os operadores de transportes.

- Descarbonização: as emissões de CO2 dos veículos pesados representam cerca de $30 \%$ de todas as emissões do transporte rodoviário. Buscar soluções para reduzir essas emissões, com a possibilidade de fornecer serviços adicionais de valor agregado que reduza os custos para empresas e pessoas, melhorando as emissões e otimizando o uso de energia e infraestrutura.

- Tecnologias digitais: ressalta a busca por padrões e plataformas comuns que devem contribuir também para a melhoria da segurança nas rodovias.

A busca por elevar o nível de segurança das rodovias, além do objetivo explícito de preservar vidas, promove uma redução do custo empregado em infraestrutura de resgate e outros gastos com saúde. De acordo com [WHO, 2015], 1,2 milhões de pessoas morrem por ano em acidentes de trânsito, sendo essa a principal causa de morte entre jovens de 15 a 29 anos, e os custos governamentais envolvidos correspondem em média a 3\% do PIB dos países, sendo que em países menos desenvolvidos podem chegar a $5 \%$.

Com relação ao quesito sustentabilidade, o impacto negativo das emissões de poluentes é potencializado por congestionamentos e pelo não emprego de tecnologias limpas. De acordo com [EPA, 2014], o setor de transportes foi responsável por $26.3 \%$ das emissões de $\mathrm{CO}^{2}$ em 2014, perdendo apenas para a geração de energia industrial, responsável por $30.3 \%$.

Nas questões relacionadas à satisfação do usuário há a necessidade de uma mudança de paradigma onde as soluções, serviços e inovações devem ser orientadas ao usuário e aos seus objetivos: o trabalhador se deslocando, a família a passeio, mas também o transporte de cargas chegando com segurança e nos prazos adequados. É importante, neste sentido, avaliar o nível de satisfação deste usuário com a frequência necessária.

A Smart Transportation Alliance (STA) é uma plataforma colaborativa global sem fins lucrativos criada em 2014 para promover inovação em infraestrutura de transportes. Apesar de não ser uma organização governamental, como o USDOT, ou uma entidade de representação de diversas nações, como a Comissão Europeia, o STA 
atua na disponibilização de relatórios, promove conferências e treinamentos relacionados ao tema Rodovias Inteligentes. Em [STAa, 2015] é disponibilizada uma visão completa e bastante didática do tema, onde é possível identificar definições e conceitos destacados também pelo USDOT e pela Comissão Europeia.

O STA descreve sua visão de Rodovias Inteligentes usando uma abordagem abrangente e inclusiva ao incorporar todos os parâmetros que contribuem para a melhoria da infraestrutura das rodovias. Desta forma, estabelece que Rodovias Inteligentes devem atender às mais altas expectativas da população em relação ao transporte rodoviário, definindo, assim, o modelo para uma rodovia que se adapte às demandas da sociedade.

Os atributos das Rodovias Inteligentes podem ser estruturais, com direta influência no projeto, construção e manutenção da rodovia; ou subjetivos, relacionados a percepções dos usuários que devem ser considerados para que sejam traduzidos em aspectos estruturais. Isso pode ser visualizado na Figura 1, onde o círculo interno corresponde aos atributos subjetivos e o externo aos atributos estruturais:

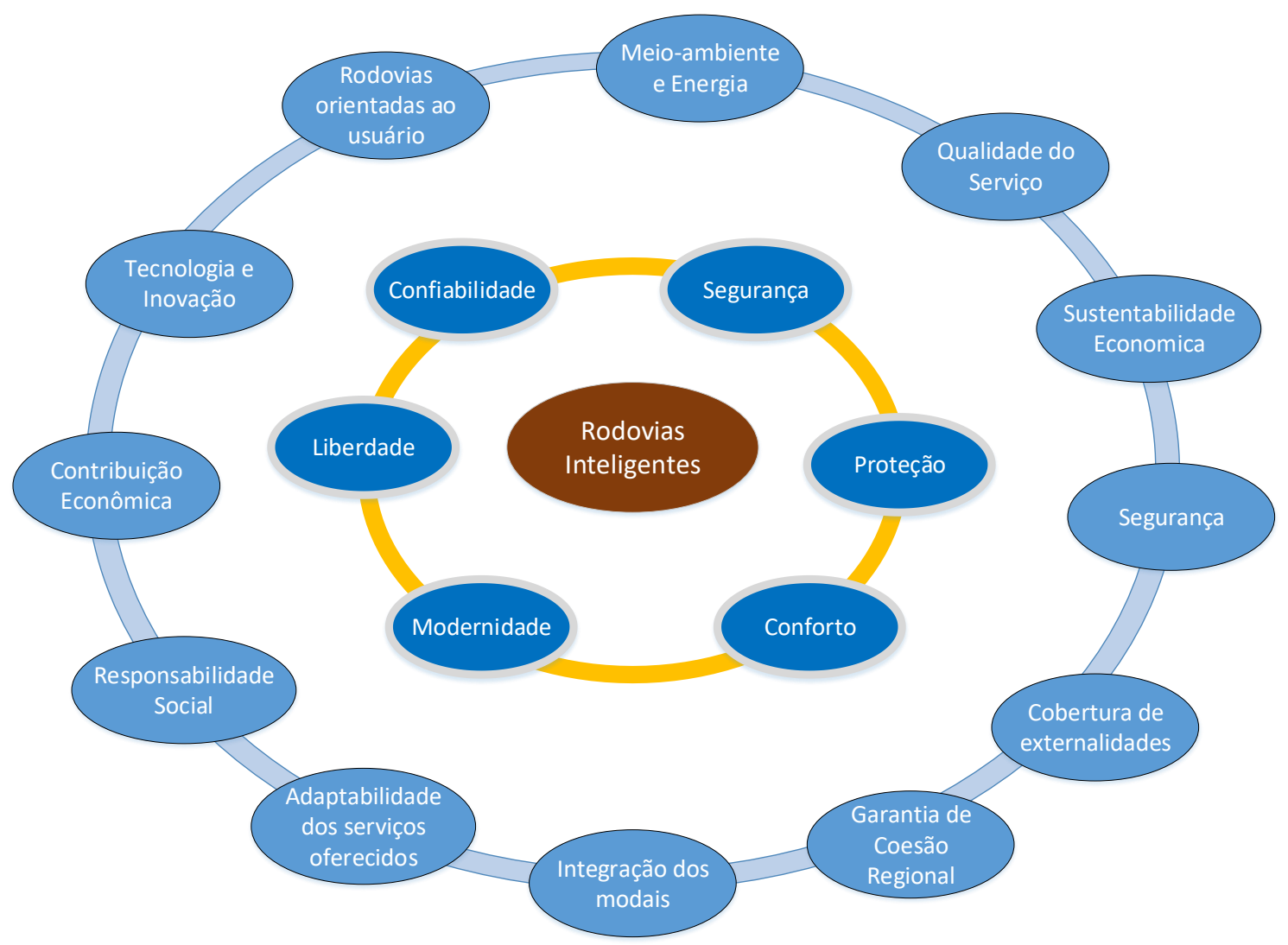

Figura 1. Atributos chave das Rodovias Inteligentes - Adaptado de [STAa, 2015]

Ao analisar os temas estruturais do STA é possível verificar que todos se relacionam a pelo menos um dos três conceitos: sustentabilidade, segurança e satisfação do usuário. Na Tabela 1 pode ser verificado um resumo das relações identificadas nesta análise.

Tabela 1. Resumo dos atributos estruturais das Rodovias Inteligentes Elaborado pelos autores 


\begin{tabular}{|l|c|c|c|}
\hline & $\begin{array}{c}\text { Relacionado } \\
\text { com } \\
\text { Sustentabilidade }\end{array}$ & $\begin{array}{c}\text { Relacionado } \\
\text { com Segurança }\end{array}$ & $\begin{array}{c}\text { Relacionado com } \\
\text { Satisfação } \\
\text { do Usuário }\end{array}$ \\
\hline Meio ambiente e Energia & $\mathrm{X}$ & $\mathrm{X}$ & $\mathrm{X}$ \\
\hline Qualidade do Serviço & $\mathrm{X}$ & & \\
\hline Sustentabilidade Econômica & & $\mathrm{X}$ & $\mathrm{X}$ \\
\hline Segurança & & $\mathrm{X}$ & $\mathrm{X}$ \\
\hline Cobertura de externalidade & $\mathrm{X}$ & & $\mathrm{X}$ \\
\hline Garantia de Coesão Regional & $\mathrm{X}$ & & \\
\hline Integração dos modais & & $\mathrm{X}$ & $\mathrm{X}$ \\
\hline Adaptabilidade dos Serviços Oferecidos & $\mathrm{X}$ & & $\mathrm{X}$ \\
\hline Responsabilidade Social & $\mathrm{X}$ & & $\mathrm{X}$ \\
\hline Contribuição Econômica & $\mathrm{X}$ & & $\mathrm{X}$ \\
\hline Tecnologia e Inovação & & & \\
\hline Rodovias Orientadas ao Usuário & & & \\
\hline
\end{tabular}

Em [STAb, 2015] foi proposta uma agenda, de 2015 à 2025, contendo 116 prioridades em P\&D (Pesquisa e Desenvolvimento) classificadas em 3 grupos de inovação, a saber:

- Construção e Operação Inteligentes e Verdes: iluminação LED (Light Emitter Diode), corredores verdes, pavimentos que combatam poluentes, adaptação à nova geração de veículos (autônomos e conectados) e às fontes de energia não convencionais. Exemplos atuais são os testes com pavimentos solares e as pistas que "abastecem" carros elétricos por indução eletromagnética. Os carros elétricos são um caminho sem volta a partir da resolução do problema da autonomia. Um exemplo disso é a lei aprovada em 2015 na Holanda, para banir a venda de veículos emissores de gases a partir de 2025. Em 2016, 10\% da frota holandesa já era de carros elétricos.

- Segurança da infraestrutura rodoviária: itens como automatização da manutenção da rodovia, sistemas de monitoramento inteligentes aptos a coletar e entregar informações, iluminação e sinalização inteligente, adaptação da rodovia para proteger usuários vulneráveis, aprofundar estudos sobre a integração pneu-pavimento, definir a geometria ótima para velocidades variadas, possibilidades de rodovias sem limites de velocidade, análises estatísticas avançadas em riscos de acidentes, entre outros.

- Mobilidade e Integração dos Modais: é preciso ir muito além do binômio "câmeras e radares", com ITS (Intelligent Transportation Systems) orientados ao usuário, práticos e acessíveis. Acelerar o desenvolvimento de sensores avançados e sistemas de monitoramento da mobilidade, facilitando o transporte de carga e pessoas entre modais e cruzando fronteiras. Tornar realidade a integração V2V (Veículo-para-Veículo) e V2I (Veículo-paraInfraestrutura) e outras possibilidades de conectividade com o ambiente externo à rodovia. Desenvolver sistemas cooperativos, mas que operem em um framework comum, com claras responsabilidades. Buscar modelos de negócios para cobrar pelo uso da infraestrutura (o chamado eRoad Eletronic Road 2.0). 


\section{Sistemas Inteligentes de Transporte}

Segundo [Sato et al., 2016], o uso da tecnologia da informação em veículos acontece de duas maneiras: na melhoria do desempenho de condução do veículo, de modo que alguns deles se assemelham a "computadores que se movem" e a segunda, através dos ITS (Intelligent Transportation Systems, Sistemas Inteligentes de Transportes) que fornecem serviços inovadores relacionados ao transporte, gerenciamento de tráfego e que permitem que os condutores e passageiros dos veículos sejam usuários mais bem informados e com maior acesso à tecnologia. Sistemas Inteligentes de Transporte (ITS) englobam uma grande variedade de aplicações relacionadas à comunicação, com objetivo de trazer maior segurança à viagem, minimizar impacto ambiental, melhorar a gestão do tráfego e maximizar os benefícios dos usuários em geral.

Em [Ullah, 2016], são listados exemplos de ITS nacionais ou continentais criados para endereçar os problemas de transporte: EUA (ITS America), Europa (ERTICO - ITS Europe), Japão (ITS Japan) e recentemente foi iniciada a coordenação de ações entre Ásia e Oceania (Asia-Pacific ITS). Estas estruturas promovem parcerias com entidades públicas e privadas e garantem o avanço das pesquisas, estabelecendo um plano estratégico e desenvolvendo projetos pilotos há vários anos.

Em [Neto et al., 2016] há um estudo de 4 projetos desenvolvidos na Europa, EUA, Japão e Austrália e um resumo das principais aplicações de cada um deles é apresentado na Tabela 2.

Tabela 2. Resumo das aplicações de cada iniciativa - Adaptado de [Neto et al., 2016]

\begin{tabular}{|l|c|c|c|c|}
\hline Aplicação & Europa & EUA & Japão & Australia \\
\hline Sistema de alerta de cansaço & & $\mathrm{X}$ & & \\
\hline Adaptação inteligente de velocidade & & $\mathrm{X}$ & $\mathrm{X}$ & \\
\hline Sinalização de velocidade limite variável & $\mathrm{X}$ & $\mathrm{X}$ & & \\
\hline Visão noturna melhorada & & $\mathrm{X}$ & & \\
\hline Proteção para pedestre e ciclistas em cruzamento & & $\mathrm{X}$ & & \\
\hline Sistema de aviso de colisão & $\mathrm{X}$ & $\mathrm{X}$ & $\mathrm{X}$ & $\mathrm{X}$ \\
\hline Aviso de desvio em relação à faixa ou à rodovia & & $\mathrm{X}$ & & \\
\hline Sinais de velocidade aconselhável para caminhões & & $\mathrm{X}$ & & $\mathrm{X}$ \\
\hline Alertas quanto às condições meteorológicas & $\mathrm{X}$ & $\mathrm{X}$ & $\mathrm{X}$ & $\mathrm{X}$ \\
\hline Controle adaptativo da velocidade de cruzeiro & & $\mathrm{X}$ & $\mathrm{X}$ & \\
\hline Sistema de assistência em caso de acidente & $\mathrm{X}$ & $\mathrm{X}$ & & \\
\hline Electronic Toll Collection (ETC) & & & $\mathrm{X}$ & \\
\hline Mensagens cooperativas & $\mathrm{X}$ & $\mathrm{X}$ & $\mathrm{X}$ & $\mathrm{X}$ \\
\hline Segurança em interseções & $\mathrm{X}$ & & & $\mathrm{X}$ \\
\hline In-Vehicle Information & $\mathrm{X}$ & & $\mathrm{X}$ & \\
\hline Avisos sobre eventos na pista & $\mathrm{X}$ & & $\mathrm{X}$ & $\mathrm{X}$ \\
\hline Rota dinâmica & & & $\mathrm{X}$ & \\
\hline Comunicação DSRC & $\mathrm{X}$ & $\mathrm{X}$ & $\mathrm{X}$ & $\mathrm{X}$ \\
\hline
\end{tabular}

iSys: Revista Brasileira de Sistemas de Informação (isys: Brazilian Journal of Information Systems) http://seer.unirio.br/index.php/isys/ 
ITS são fundamentais para o desenvolvimento de Rodovias Inteligentes. Foram exploradas três tecnologias já utilizadas ou com potencial de uso nestes sistemas: rede de sensores sem fio, dados coletados por sensores nos veículos e smartphones, e VANTs. Buscou-se por algumas soluções e pesquisas, bem como seus desafios e tendências que estão descritos nas subseções seguintes.

\subsection{Redes de Sensores sem Fio}

De acordo com [Ibnkahla, 2012], as categorias mais populares de redes de sensores sem fio incluem:

- WSN (rede de sensores sem fio): os nós de sensor são implantados na área de destino para medir atributos específicos, como temperatura ou pressão, e retransmitir as informações medidas para uma estação base para processamento.

- MANET (rede móvel ad hoc): os nós normalmente têm capacidades de processamento e de rede suficientes e podem se conectar de forma autônoma e executar uma variedade de aplicativos.

- WMN (rede de malha sem fio): os nós têm capacidades semelhantes às MANETs, mas algumas infraestruturas são normalmente utilizadas, principalmente para fornecer serviços de Internet a um grande número de dispositivos sem fios.

- VANET (rede veicular ad hoc): os veículos estão equipados com transceptores que podem ser usados para trocar informações como intensidade de tráfego e advertências de colisão, ou para comunicação regular de dados. As VANETs são classes especiais das MANETs, onde veículos agem como nodos em movimento, [Ullah, 2016].

Conforme descrito em [Ullah, 2016], de maneira geral, as comunicações VANET podem ser classificadas em:

- V2V (Veículo-para-Veículo): os veículos enviam mensagens para seus vizinhos com o propósito de melhorar a consciência do motorista sobre o seu entorno. Exemplos são assistência ao motorista para troca de pista, alarme de colisão, assistência na velocidade em curva, etc.

- V2I ou I2V (Veículo-para-Infraestrutura ou Infraestrutura-para-Veículo): comunicação entre o veículo e a infraestrutura existente ao longo da rodovia. $\mathrm{O}$ objetivo é informar aos motoristas as condições e riscos na rodovia, por exemplo alarme de desastre, alarme de violação de velocidade, etc.

- Comunicação híbrida (V2V e V2I/I2V): possibilita estender a área de cobertura das infraestruturas da rodovia. De acordo com [Cunha et al., 2016], dependendo da distância um veículo pode se comunicar com a infraestrutura da via de uma maneira única ou através de "saltos múltiplos" (multi-hop), ou seja, ele pode ou não acessar diretamente a unidade de comunicação da rodovia, permitindo assim a conexão de longa distância à Internet ou à veículos que estão distantes, conforme a Figura 2. 
- V2X: (Vehicles to Everything): é um termo geral designado a qualquer tipo de comunicação que envolve o veículo: V2V, V2I e outras mais como comunicação com pedestres, ciclistas, motociclistas, etc.

Veículos autônomos contém no seu interior sensores, câmaras e tecnologias de localização para operar de maneira segura sem a interferência do condutor. Já veículos conectados, não necessariamente autônomos, usam a tecnologia wireless para compartilhar informação e localização com outros veículos (V2V); com a infraestrutura (V2I) ou com outros modais, como por exemplo nuvens na internet, pedestres, ciclistas (V2X), [Auer et al., 2016].

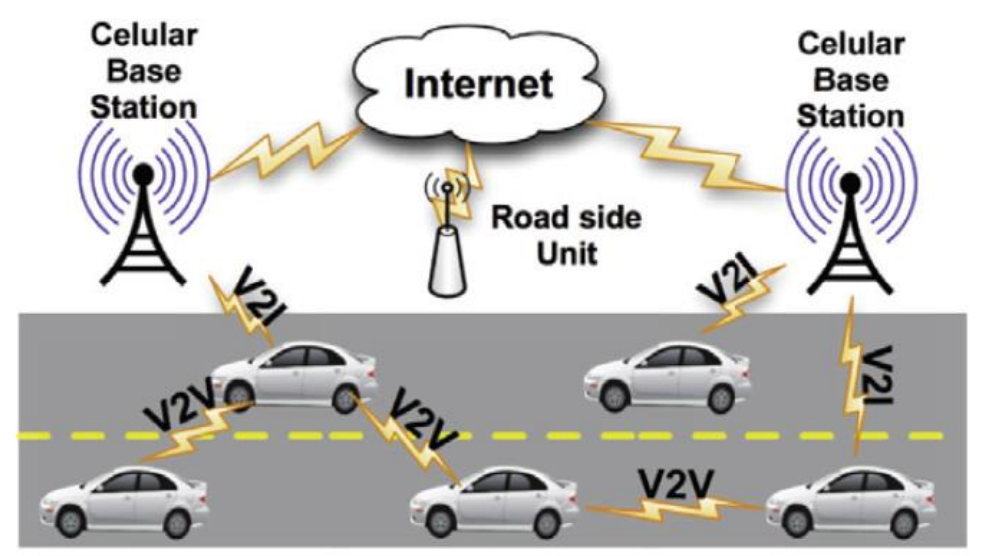

Figura 2. Arquitetura VANET híbrida - Adaptado de [Cunha et al., 2016]

Conforme [ETSI, 2012], a tecnologia wireless usada em veículos conectados é chamada DSRC (Dedicated Short-Range Communications), entretanto algumas funções podem usar o celular ou outros tipos de comunicação. DSRC consistem de Unidades Laterais (RSUs) e Unidades On Board (OBUs). As OBUs ficam dentro do veículo e possuem antena wireless para comunicações de curtas distâncias com outras OBUs e com as RSUs. As RSU são fixas ao longo da rodovia e são controladas pelo gestor da rodovia ou órgãos governamentais.

Fabricantes do mundo inteiro estão na corrida por implementar veículos autônomos e inteligentes e vem incorporando sensores, câmeras integradas, equipamentos laser, radar, lidar e GPS. Aliado a isso, tecnologias sem fio estão cada vez mais maduras facilitando a comunicação entre esses veículos inteligentes, [Ullah, 2016]. Nessa linha, a partir de maio de 2018, todos os carros produzidos nos EUA terão câmeras, isso é considerado uma questão de segurança, [Auer et al., 2016].

As comunicações V2V e V2I possibilitam uma vasta gama de aplicações para tornar o ambiente da rodovia mais seguro, sustentável e agradável ao usuário. Nas aplicações relacionadas à segurança, o envio de mensagens com avisos de problemas na rodovia com a antecedência necessária, permite que o condutor tome uma ação ou, em futuro próximo, o carro total ou parcialmente autônomo tome a ação necessária para minimizar o impacto. Em [Tientrakool e Maxemchuk, 2011] foi feito um estudo sobre o impacto do uso da tecnologia $\mathrm{V} 2 \mathrm{~V}$ e dos sensores do veículo que assistem o motorista para evitar colisões. Somente o uso dos sensores do veículo proporcionaram um 
aumento da capacidade da rodovia de $43 \%$, enquanto que usando esses sensores combinados à V2V o aumento da capacidade é de $273 \%$.

Fenômenos de neblina e nevoeiro são responsáveis por acidentes de trânsito graves, envolvendo vários veículos e sua ocorrência é relativamente comum nas rodovias em montanhas ou em regiões úmidas e frias. Em [Li et al., 2014] é apresentado um sistema que identifica a baixa visibilidade e notifica os condutores do limite de velocidade adequado, antes que os mesmos se deparem com o fenômeno. Na Figura 3 é possível visualizar a arquitetura de comunicação baseada em rede de sensores sem fio.

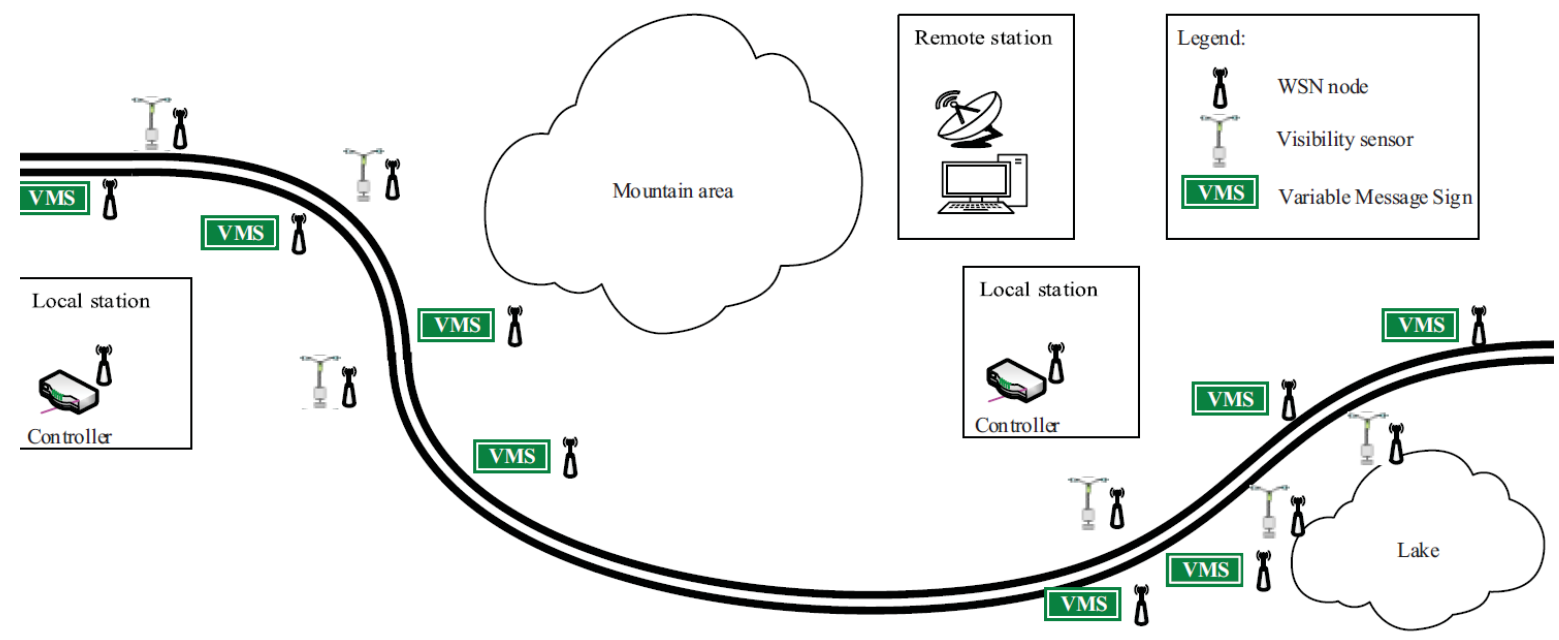

Figura 3. Sistema de detecção e alerta de Nevoeiro - Extraído de [Li et al., 2014]

Ainda no contexto de segurança, redes de sensores sem fio são usadas para o monitoramento de obras de engenharia como pontes das rodovias. Vários trabalhos existem a respeito e soluções comerciais também. Está descrito em [Al-Radaideh et al., 2015] um sistema de monitoramento sem fio para pontes de rodovias. O sistema utilizou uma unidade de aquisição de dados baseada em ZigBee, uma rede de comunicação GPRS (General Packet Radio Services) e um sistema de controle baseado em lógica fuzzy.

Outra aplicação relacionada à segurança é tratada em [Lira, 2016]. O TSMA (Traffic Sign Management Architecture) é uma arquitetura de gestão da sinalização de trânsito que permite uma real adaptação das placas ao contexto do trânsito. Os veículos adaptados ao TSMA são equipados com receptor que exibe as placas de trânsito ao motorista em uma tela no painel, o que dá destaque e minimiza risco de acidentes. Uma implementação em larga escala permitiria efetuar remotamente mudanças na sinalização de trânsito para desviar o fluxo de veículos em caso de acidentes ou mesmo aumentar a velocidade de uma via em horários específicos.

As aplicações de veículos conectados não se limitam à área da segurança. Em [Ullah, 2016], por exemplo, há uma proposta de aplicações de entretenimento com foco maior em publicidade e na descoberta dos serviços disponíveis na rodovia.

\section{2. "Probe Vehicle Data" e "Mobile sensing"}

"Probe Vehicle Data", também conhecido como "Floating Car Data", se refere aos dados coletados pelos diversos sensores existentes nos veículos e contém pelo menos 
informações de posição, podendo incluir informações de tração, aceleração, velocidade, ações do condutor (direção, frenagem), clima e condições da superfície da estrada, etc., [Sato et al., 2016]. Os dados são processados estatisticamente podendo ser usados nos ITS para calcular a taxa de fluxo de tráfego, além de serem usados para prover informações das condições da rodovia e também para simulações futuras. Adicionalmente, sistemas baseados em dados dos sensores dos veículos são extremamente efetivos em situações de desastre gerando mapas da rodovia ativos, como no caso do terremoto do Japão em 2011, onde foi possível compreender os danos no sistema viário usando probe data e gerando mapas ativos das vias, conforme ilustra a Figura 4.

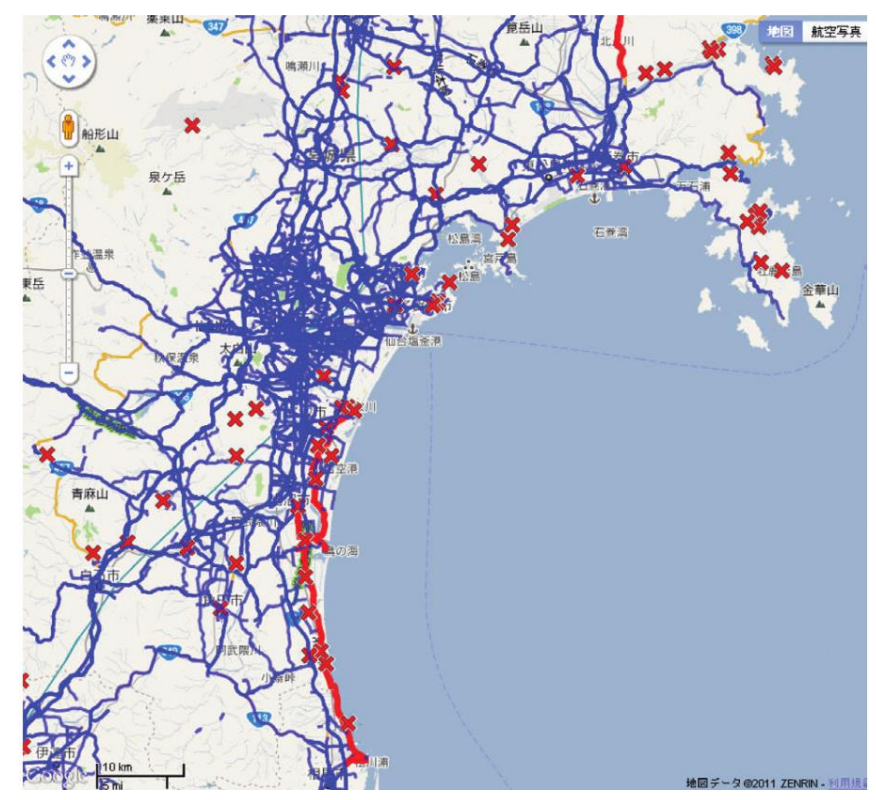

Figura 4. Mapa ativo feito com probe data - Extraído de [Sato et al., 2016]

Um dos desafios apontados desde FHWA [1998], são as questões de privacidade pois as técnicas do probe vehicle data envolvem o acompanhamento de veículos à medida que viajam pela rodovia. Isso suscita, por exemplo, preocupações de que os motoristas possam ter mais chances de receber multas de tráfego ou ter seus hábitos de viagem monitorados.

O termo "Mobile Sensing" se refere às tecnologias de detecção móveis utilizando dados coletados por sensores existentes nos smartphones como GPS, acelerômetro, giroscópio, etc. Em [Shaohan et al., 2015], é exemplificado o uso de mobile sensing para analisar o comportamento dos condutores e detectar padrões, como, por exemplo, identificar reguladores de trânsito como semáforos e locais de parada obrigatória através de dados coletados dos sensores GPS existentes nos smartphones dentro dos veículos. Esses dados são processados com a aplicação de métodos estatísticos para a determinação dos locais de atenção, possibilitando assim o alerta ao motorista.

Em [Yi et al., 2015] é descrito um sistema para detectar e avaliar anomalias da superfície da estrada, como buracos e solavancos. Foi introduzida uma técnica de processamento do sinal para extrair as componentes verticais da aceleração obtidas do acelerômetro do smartphone. 


\subsection{Veículos Aéreos Não Tripulados - VANTs}

Segundo [Custers, 2016], Veículos Aéreos Não Tripulados (VANTs), também conhecidos como drones, têm recebido uma recente atenção da mídia sugerindo que se trata de uma nova tecnologia. Entretanto, drones têm sido usados para fins militares há várias décadas. O que é novo, todavia, é o fato de que hoje são pequenos, relativamente baratos e facilmente disponíveis.

As aplicações desta tecnologia hoje são as mais diversas: agricultura de precisão, segurança, vigilância. Mas há um vasto leque de possibilidades elencado em [Vergouw et al., 2016], como por exemplo em desastres ou crises, onde os drones ajudam na coleta de informações, ou na proteção de ambientes críticos e perigosos como áreas nucleares ou de difícil acesso. Existem projetos em estágios iniciais para a entrega de produtos e serviços por drones, como os exemplos da Amazon e Walmart ${ }^{1}$. De acordo com [Applin, 2016], entregar produtos através de drones para os consumidores envolve complexidades práticas, sociais e éticas. A autora enfatiza que, além de questões de privacidade e segurança, grande parte do que está sendo considerado por estas empresas como a "entrega dos sonhos" são imaginados em cenários individuais que não levam em consideração a complexidade de um conjunto de drones no espaço público.

Segundo [Vergouw et al., 2016], VANTS podem ser muito úteis nas inspeções e manutenção de infraestrutura de estradas, ferrovias, pontes, oleodutos e barragens. Manchas fracas, erosão ou desgaste podem ser detectadas com câmeras. O movimento de veículos, aeronaves e navios, pode ser facilmente monitorado. Assim, no que se refere a ITS para rodovias existe uma vasta possibilidade de aplicações para drones relacionadas a trazer mais mobilidade em funções como: comunicação de acidentes, câmaras que se deslocam e podem ser os olhos do policial ou auxiliar o gestor da via no monitoramento da mesma, avaliando pontos de manutenção de forma eficiente.

No trabalho [Menouar et al., 2017], são apresentadas possibilidades de uso de VANTs voando juntos, de maneira coordenada, colaborando para executar uma missão específica. Agindo em grupo, o problema da limitação de energia pode ser superado usando algoritmos de otimização das tarefas. Na Figura 5, é possível observar um cenário exemplo de VANTs integradas ao ITS, usando comunicação wireless e onde alguns são RSUs voadoras que efetuam gravações de vídeo e as enviam a um centro de mobilidade.

\footnotetext{
${ }^{1}$ https://qz.com/1058907/walmart-following-amazon-filed-for-a-patent-to-send-out-delivery-drones-froma-distribution-center-in-the-sky-wmt-amzn/

isys: Revista Brasileira de Sistemas de Informação (isys: Brazilian Journal of Information Systems) http://seer.unirio.br/index.php/isys/
} 


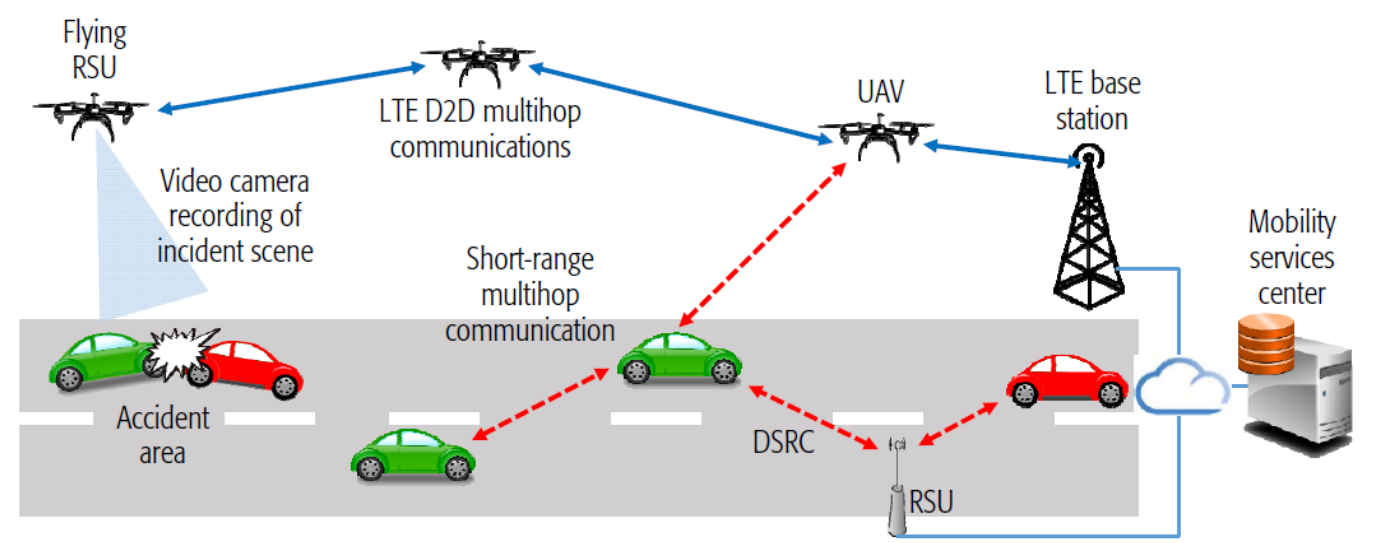

Figura 5. Proposta de uso coordenado de VANTs - Extraído de [Menouar et al., 2017]

Ainda segundo [Menouar et al., 2017], as principais limitações no uso de VANTs são a energia, onde algoritmos bem elaborados podem otimizar as tarefas dividindo as responsabilidades; a baixa velocidade, no caso de rodovias isso poderia ser compensado com voos altos, e a capacidade de processamento e a transmissão do sinal, que deverão ser superadas em futuro próximo. Dependendo dos locais de implantação de um sistema como este, as questões de legislação e ética relacionada a privacidade, serão desafios maiores do que questões técnicas.

\section{4. $O$ contexto das rodovias brasileiras}

Ao todo, o território nacional tem cerca de 1.750 .000 quilômetros de rodovias, distribuídas conforme Quadro 1.

Quadro 1. Distribuição das Rodovias Brasileiras - Adaptado de [MTPAa, 2015]

\begin{tabular}{|l|l|l|}
\hline \multirow{4}{*}{$\begin{array}{l}\text { Quanto a } \\
\text { Pavimentação }\end{array}$} & Pavimentadas & $13 \%$ \\
\cline { 2 - 3 } & Não pavimentadas & $79 \%$ \\
\cline { 2 - 3 } & Planejadas & $8 \%$ \\
\hline \multirow{3}{*}{ Quanto à gestão } & Estaduais & $15 \%$ \\
\cline { 2 - 3 } & Municipais & $78 \%$ \\
\cline { 2 - 3 } & Federais & $7 \%$ \\
\hline
\end{tabular}

Os investimentos na infraestrutura de transportes no país em 2015 foram de 26,6 bilhões sendo que para o transporte rodoviário estava previsto $45 \%$ do total [MTPAb, 2017]. Apesar dos investimentos o País está muito distante do que se pode chamar de rodovias inteligentes, os problemas vão desde sinalização inadequada, buracos na pista, construções indevidas nas proximidades da rodovia, esgotos municipais interligados de maneira clandestina no sistema de drenagem pluvial rodoviário e depósito de lixo ao longo do trecho pelos usuários e transeuntes, fato este que acaba por causar alagamentos em locais destinados ao tráfego de veículos na via, maximizando os riscos de acidentes.

De acordo com pesquisa efetuada pela Agência Nacional de Transportes Terrestres [ANTT, 2014], responsável por fiscalizar as concessões efetuadas no âmbito Federal, o nível médio de satisfação do usuário é de $62 \%$, sendo que $43 \%$ dos trechos se encontram com índice de satisfação abaixo de $60 \%$, tendo, portanto, um grande espaço 
para melhorias também nas rodovias com pedágio. A pesquisa ocorreu em 2014 e avaliou 14 concessionárias em 49 trechos, os quais foram classificados segundo 8 categorias que podem ser verificadas na Tabela 3. No total foram pesquisados 7.184 condutores de veículos leves e 4.763 condutores de veículos pesados.

Tabela 3. Média nacional por categoria da Pesquisa de Satisfação- Adaptado de [ANTT, 2014]

\begin{tabular}{|l|c|}
\hline Categoria & $\begin{array}{c}\text { Índice de } \\
\text { Satisfação }\end{array}$ \\
\hline Pista & $59,4 \%$ \\
\hline Sinalização & $64,0 \%$ \\
\hline Fluidez & $60,3 \%$ \\
\hline Segurança & $60,9 \%$ \\
\hline
\end{tabular}

\begin{tabular}{|l|c|}
\hline Categoria & $\begin{array}{c}\text { Índice de } \\
\text { Satisfação }\end{array}$ \\
\hline Serviços & $63,7 \%$ \\
\hline Limpeza & $67,7 \%$ \\
\hline Fiscalização & $56,3 \%$ \\
\hline Pedágio & $56,2 \%$ \\
\hline
\end{tabular}

A pesquisa de rodovias da Confederação Nacional de Transportes, [CNT, 2016], abrange toda a extensão da malha pavimentada federal e as principais rodovias estaduais pavimentadas. Dos $103.259 \mathrm{~km}$ analisados, constatou-se que 48,3\% apresentam algum tipo de problema nas condições do pavimento, possuindo classificações regular, ruim ou péssimo. Com respeito a sinalização esse índice é de 51,7\%. Na [CNT, 2016] são identificados pontos críticos nas rodovias como trechos com buracos grandes, quedas de barreiras, pontes caídas e erosões. Constatou-se um aumento de 26,6\% de 2015 para 2016 nos pontos críticos, passando de 327 para 414.

O DNIT desempenha papel fundamental dentro da estrutura do Ministérios dos Transportes, Portos e Aviação Civil, onde é responsável por implementar a política de infraestrutura do Sistema Federal de Viação, compreendendo sua operação, manutenção, restauração ou reposição, adequação de capacidade e ampliação mediante construção de novas vias e terminais [DNITa, 2017].

Em [DNITb, 2017] pode ser verificado o ICM (Índice de Condição da Rodovia) que foi calculado sobre mais de $52.000 \mathrm{~km}$ de rodovias federais, revelando um índice de $33 \%$ de trechos em classificação regular, ruim ou péssimo. Na Figura 6 é possível identificar uma variação importante neste índice nos estados brasileiros.

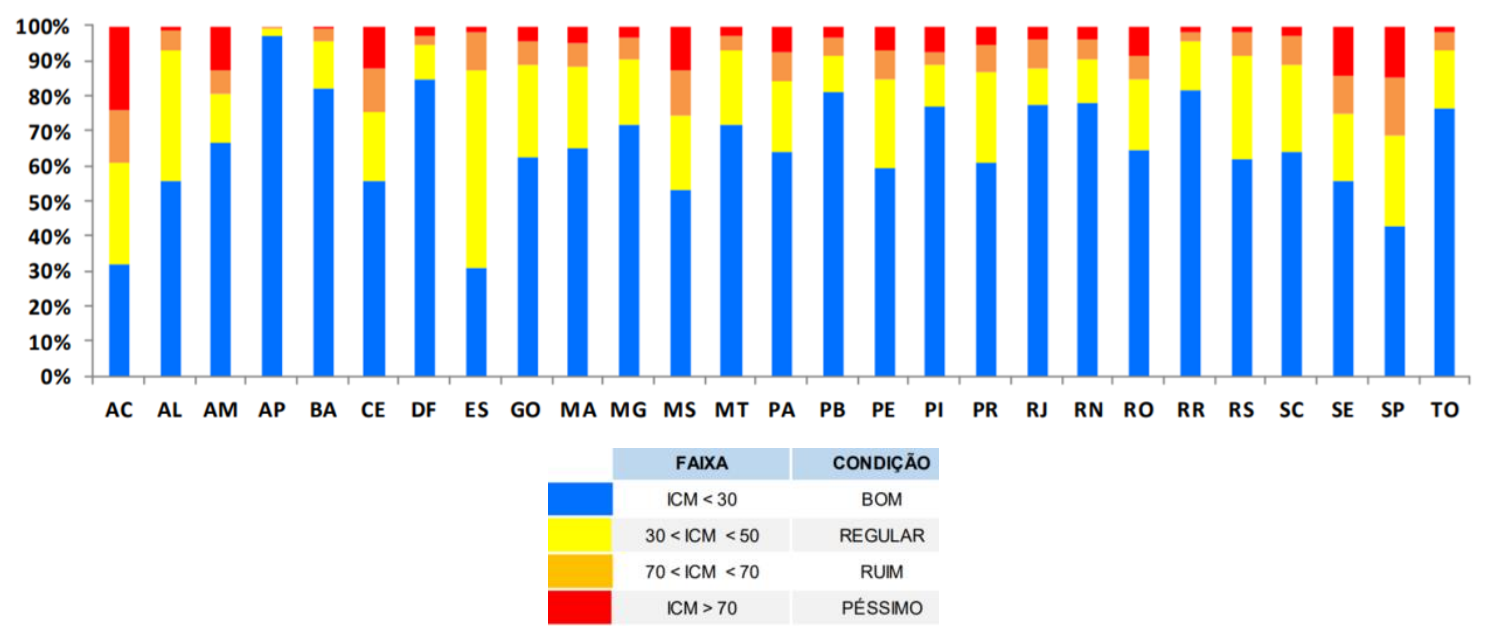

Figura 6. Índice de Condição da Rodovia por Estado - Extraído de [DNITb, 2017] 
Segundo [DNITb, 2017], os critérios usados para avaliação do pavimento levam em consideração a ocorrência e frequência de defeitos no pavimento. Os critérios para avaliação da conservação consideram a situação da roçada (altura da vegetação), da drenagem (dispositivos superficiais) e da sinalização (elementos verticais e horizontais). Desta forma, o ICM é obtido a partir da soma do índice do pavimento, que tem maior peso (70\%), com o índice da conservação, e é classificado em uma das faixas a seguir:

- $\mathrm{ICM}<$ 30: a rodovia apresenta bom estado de manutenção e requer apenas serviços de conserva rotineira.

- ICM entre 30 e 50: a rodovia apresenta situação regular e requer serviços de conserva leve.

- ICM entre 50 e 70: a rodovia está em estado ruim de manutenção e requer serviços de conserva pesada - nível 1.

- ICM > 70: a rodovia é considerada em estado péssimo, o que requer serviços de conserva pesada nível 2 (mais profunda).

Visando a melhoria da situação das rodovias brasileiras, o DNIT participa ou lidera pesquisas relacionadas ao tema, como por exemplo o VDR (Veículo de Diagnóstico Rodoviário) e o PIAF (Postos Integrados Automatizados de Fiscalização). O VDR é responsável por coletar informações do Índice de Irregularidade Internacional (IRI), o Registro em Vídeo e o Levantamento Visual Contínuo (LVC) da Malha Rodoviária Federal e por alimentar o banco de dados do Sistema de Gerência de Pavimentos (SGP). Em 2012, o VDR entrou em plena operação, otimizando o método de avaliação das condições dos pavimentos rodoviários com redução de mais de $50 \%$ dos custos [DNIT, 2015].

O PIAF é uma pesquisa iniciada em 2013 em parceria com a Universidade Federal de Santa Catarina para o desenvolvimento da tecnologia a ser utilizada nos Postos Integrados Automatizados de Fiscalização (PIAF), destinados a pesagem de veículos de carga. Um dos principais fatores na deterioração do pavimento das rodovias é o excesso de cargas nos caminhões. A implantação destes postos, bem como a continuidade da pesquisa, impactará positivamente o sistema nacional de viação. $\mathrm{O}$ PIAF usa sensores que permitem a pesagem com veículo em movimento: uma préseleção acontece com os caminhões trafegando a $60 \mathrm{~km} / \mathrm{h}$ e para os selecionados a pesagem é feita entre 5 e $10 \mathrm{~km} / \mathrm{h}$ [LABTRANS, 2015].

Atualmente dispositivos como câmeras, controladores de velocidade e contadores de tráfego são amplamente utilizados nas rodovias pavimentadas brasileiras. De acordo com [ANTT, 2017] está em processo a operacionalização da identificação eletrônica dos veículos automotores de cargas, cujo cadastro de condutores já é obrigatório, devendo estes apresentar o Registro Nacional de Transportadores Rodoviários de Cargas (RNTRC) e num futuro próximo, por intermédio da instalação de tags de RFID (Radio-Frequency Identification) nestes veículos, será possível esta identificação, visando o controle de peso das cargas e podendo vir a colaborar também com questões de segurança relacionas ao roubo de cargas. A operação remota será executada a partir desta identificação e no Centro de Controle Operacional (CCO) das empresas que detém a concessão das rodovias serão utilizados Sistemas Automatizados Integrados (SAI), tais como vídeomonitoramento, câmeras de reconhecimento e 
identificação automática de placas de veículo, leitores de tags de identificação, painéis de mensagem variáveis na via, indicando a entrada obrigatória na área destinada à pesagem e painéis de informação eletrônicos no pátio do posto de fiscalização, dispondo de orientações e informações aos condutores, contabilizando qual foi o excesso de peso e indicando qual a medida necessária para sanar a inconformidade, [ANTT, 2017].

\section{Desafios na Implementação de Sistemas Inteligentes de Transportes}

Segundo [Picone et al., 2015], um dos maiores desafios para o ITS é a busca por um ambiente cooperativo (C-ITS), com segurança e compartilhamento dos dados entre todas as aplicações desenvolvidas pelos diversos atores independentes. A realização dos ITS envolve um alto número de atores, desde a administração pública, autoridades em transporte e empresas de vários setores como fabricantes de veículos e OEM (Original Equipment Manufacturer), empresas de telecomunicações, provedores de serviços, etc. Dentro da perspectiva industrial e tecnológica os ITS são considerados um dos grandes desafios da comunidade TIC, portanto a presença de padrões mundiais é requisito chave para explorar toda a sua potencialidade. Desde 1990 existe um esforço para a padronização envolvendo várias organizações como IEEE (Institute of Electrical and Electronics Engineers), ISO (International Organization for Standardization), CEN (European Committee for Standardization), ETSI (European Telecommunications Standards Institute), entre outros. Na Figura 7 é possível visualizar os diversos componentes da arquitetura ITS, descrita na ISO 21217, baseado no conceito de estação ITS (ITS Station, ITS-S) que são unidades computacionais modulares com capacidades de comunicação. Os ITS-S podem ser agrupados em:

- Vehicle ITS Stations: sistemas embarcados nos veículos em movimento ou estacionados.

- Roadside ITS Stations: unidades instaladas ao longo da rodovia, nos acessos, junto a sinalização de trânsito.

- Central ITS Remote Stations: estações remotas que são chave na gestão centralizada dos serviços de ITS: coleta, armazena e processa a informação.

- Personal ITS Stations: dispositivos de mão ou nômades como, smartphones e tablets. 


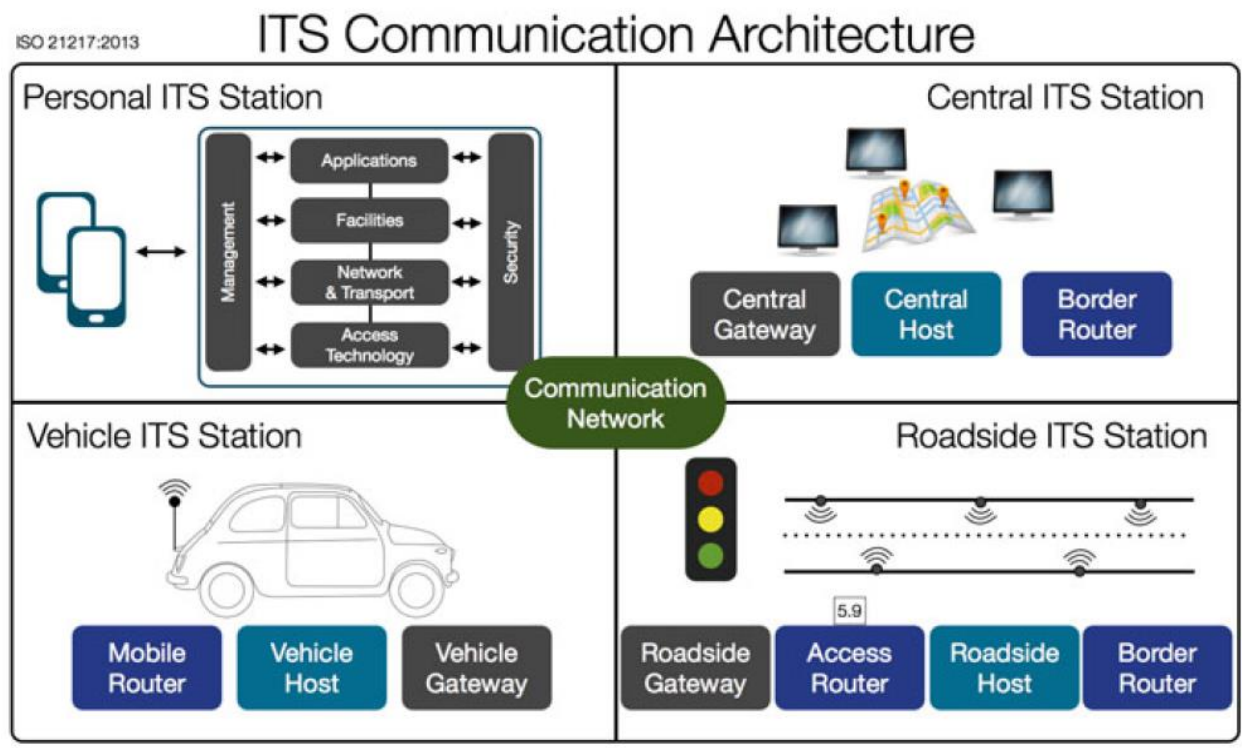

Figura 7. Principais componentes do ITS - Extraído de [Picone et al., 2015]

De acordo com [Picone et al., 2015], à medida que os veículos se integram a um ITS, um ecossistema de aplicativos totalmente novo pode ser criado, e mesmo as aplicações pré-existentes podem melhorar sua eficiência. As aplicações componentes dos ITS podem ser classificadas em três categorias: segurança de transporte, eficiência de transporte e serviços aos usuários nos veículos, tipicamente no campo de conectividade e conveniência.

A interoperabilidade dos sistemas inteligentes de transportes é especialmente importante a nível nacional para garantir que os sistemas de transporte forneçam aos viajantes desempenho consistente e confiável, independentemente dos seus veículos, do modo de transporte ou da rota. Dessa forma, diante da grande complexidade do ITS, é necessária uma abordagem de engenharia de software profunda, pois sistemas complexos usualmente são hierárquicos e incluem outros sistemas, os subsistemas, que podem operar de forma independente, [Sommerville, 2011]. Um exemplo disso são os sistemas de informação geográfica que são utilizados por vários sistemas componentes dos ITS. A abordagem fracamente acoplada para estes subsistemas é importante para uma entrega mais rápida, barata e eficiente baseado no reuso dos componentes.

A implementação das redes veiculares VANET apresenta como principais desafios a alta mobilidade dos veículos, o que demanda um grande esforço para manter mapas de topologia de rede atualizados, e a variabilidade do ambiente (áreas com alta reflexão, túneis, etc.). Além disso, a segurança cibernética é questão fundamental nos sistemas conectados e autônomos, e tem sido uma preocupação dos fabricantes e também das organizações envolvidas no estabelecimento dos padrões.

Além dos desafios mencionados sobre arquitetura, segurança, questões físicas da rede de sensores e interoperabilidade dos componentes do ITS é fundamental a clareza do papel e dos requisitos atendidos por cada subsistema, nas diferentes localidades, para os diferentes perfis de usuário. Especialmente para países em desenvolvimento como o Brasil, esse tema deve receber especial atenção em virtude da necessidade de sistemas capazes de apoiar a gestão da rodovia, fornecendo ferramentas para monitoramento das condições da mesma e da conservação da sua infraestrutura. Esses processos devem ser 
discutidos dentro da realidade local do gestor e dos usuários, de forma a oferecer soluções de alto valor agregado, trazendo os benefícios certos, os quais podem ser soluções não inovadoras em âmbito mundial, mas inovadoras na região que devem suportar.

$\mathrm{Na}$ Tabela 4 é possível verificar um resumo das tecnologias relacionadas a ITS abordadas neste trabalho, considerando sua aplicação no Brasil e no restante do mundo, bem como principais desafios.

Tabela 4. Resumo das tecnologias abordadas - Elaborado pelos autores

\begin{tabular}{|c|c|c|c|}
\hline Tecnologia & Mundo & Brasil & Desafios \\
\hline $\begin{array}{l}\text { Rede de } \\
\text { sensores } \\
\text { sem fio }\end{array}$ & $\begin{array}{l}\text { Várias pesquisas mundiais } \\
\text { relacionadas ao tema. } \\
\text { Projetos pilotos ocorrem ao redor } \\
\text { do mundo, como Virginia Smart } \\
\text { Road }^{2} \text { e o Corredor Rotterdam- } \\
\text { Frankfurt/M. - Vienna }{ }^{3} \text {. }\end{array}$ & $\begin{array}{l}\text { Existem pesquisas } \\
\text { brasileiras relacionadas ao } \\
\text { tema como visto em [Lira, } \\
\text { 2016] e [Ullah 2016]. } \\
\text { Não foi identificado por } \\
\text { este trabalho um projeto } \\
\text { piloto em algum trecho } \\
\text { rodoviário brasileiro. }\end{array}$ & $\begin{array}{l}\begin{array}{l}\text { Manter topologia } \\
\text { rede atualizada }\end{array} \\
\text { virtude da alta } \\
\text { mobilidade } \\
\text { veículos. } \\
\text { Variabilidade } \\
\text { ambiente (áreas com } \\
\text { alta reflexão, túneis, } \\
\text { etc.). } \\
\text { Segurança cibernética. }\end{array}$ \\
\hline $\begin{array}{l}\text { Probe } \\
\text { Vehicle } \\
\text { Data } \\
\text { e } \\
\text { Mobile } \\
\text { Sensing }\end{array}$ & $\begin{array}{l}\text { Já está em uso, como no exemplo } \\
\text { citado do Japão. Empresas como } \\
\text { Tom Tom }{ }^{4} \text { e Microsoft }{ }^{5} \text { tem } \\
\text { estabelecido parcerias com os } \\
\text { fabricantes de veículos. } \\
\begin{array}{l}\text { Diversas pesquisas } \\
\text { andamento que utilizam os } \\
\text { sensores dos smartphones, em } \\
\text { especial GPS e acelerômetro. }\end{array}\end{array}$ & $\begin{array}{l}\text { A SPtrans }{ }^{6} \text { possui uma } \\
\text { aplicação dos dados } \\
\text { gerados pelos } \text { GPS } \\
\text { existentes na frota de } \\
\text { ônibus urbanos de São } \\
\text { Paulo. } \\
\text { Dentro das aplicações para } \\
\text { rodovias podemos destacar } \\
\text { o aplicativo da ARTESP }{ }^{7} \text { e } \\
\text { do DNIT }{ }^{8} \text { que possibilitam } \\
\text { informar os incidentes nas } \\
\text { rodovias. }\end{array}$ & $\begin{array}{l}\text { Heterogeneidade dos } \\
\text { dados. } \\
\text { No caso dos dados dos } \\
\text { sensores dos veículos a } \\
\text { padronização } \\
\text { envolvendo os vários } \\
\text { fabricantes } \\
\text { fundamental } \\
\text { garantir } \\
\text { interoperabilidade. } \\
\text { Privacidade } \\
\text { indivíduos. }\end{array}$ \\
\hline VANT & $\begin{array}{l}\text { Os VANTS são uma realidade, } \\
\text { mas há várias restrições legais }\end{array}$ & $\begin{array}{l}\text { O Brasil } \\
\text { acompanhando }\end{array}$ & $\begin{array}{l}\text { Privacidade } \\
\text { responsabilidades }\end{array}$ \\
\hline
\end{tabular}

\footnotetext{
${ }^{2}$ https://www.vtti.vt.edu/facilities/virginia-smart-road.html

${ }^{3} \mathrm{http}: / / \mathrm{c}-$ its-korridor.de/?menuId=1\&sp=en

${ }^{4}$ https://automotive.tomtom.com/success-stories/toyota-success-story/

${ }^{5} \mathrm{https}$ //news.microsoft.com/pt-br/plataforma-de-veiculos-conectados-da-microsoft-ajuda-fabricantes-atransformarem-seus-automoveis/

${ }^{6} \mathrm{http}: / /$ olhovivo.sptrans.com.br/

${ }^{7} \mathrm{http}: / /$ www.artesp.sp.gov.br/rodovias-aplicativo-eu-vi.html

${ }^{8} \mathrm{http}: / /$ www.dnit.gov.br/planejamento-e-pesquisa/dnit-movel/dnit-movel

iSys: Revista Brasileira de Sistemas de Informação (iSys: Brazilian Journal of Information Systems) http://seer.unirio.br/index.php/isys/
} 


\begin{tabular}{|c|c|c|c|}
\hline & $\begin{array}{l}\text { que estão sendo discutidas, } \\
\text { especialmente em torno do uso } \\
\text { fora da linha de visada do piloto. } \\
\text { Diversos países consideram } \\
\text { drones na sua legislação de } \\
\text { aviação, como os USA }{ }^{9} \text {, onde } \\
\text { agências de segurança e defesa } \\
\text { civil já usam a tecnologia, } \\
\text { inclusive em rodovias }{ }^{10} \text {. } \\
\text { Não foram identificados por este } \\
\text { trabalho aplicações com o uso de } \\
\text { drones operando em conjunto } \\
\text { como proposto por [Menouar et } \\
\text { al., 2017]. }\end{array}$ & $\begin{array}{l}\text { discussões e pesquisas } \\
\text { mundiais sobre o tema. A } \\
\text { legislação teve mudanças } \\
\text { recentes }^{11} \text {. } \\
\text { A Polícia Rodoviária } \\
\text { Federal }^{12} \text { está testando a } \\
\text { tecnologia para uso }_{\text {também em rodovias. }}\end{array}$ & $\begin{array}{l}\text { envolvidas em caso de } \\
\text { acidentes ou mau uso } \\
\text { intencional. } \\
\text { Autonomia de voo. } \\
\text { Segurança cibernética. }\end{array}$ \\
\hline
\end{tabular}

\section{Considerações Finais}

As próximas duas décadas trarão grandes evoluções nos países desenvolvidos no que tange às rodovias inteligentes, especialmente pelo potencial de crescimento do carro elétrico e inserção dos veículos conectados e autônomos. Adaptar as rodovias para isso consta nos planos estratégicos de vários ITS nacionais ou continentais e sistemas de informação bem projetados e capazes de administrar os dados gerados pelas diversas unidades computacionais envolvidas são condição para a execução destas estratégias.

O grande motivador na evolução dos ITS tem sido a segurança, mas devem se fortalecer aplicações orientadas à satisfação do usuário e ligadas à sustentabilidade. As tendências apontam para o transporte como um serviço, como já acontece em outros segmentos, e isso poderá mudar a relação de propriedade das pessoas com os veículos. Essa mudança ocorrerá também no estilo de vida, visto que o carro não será mais uma preocupação, e o tempo dedicado aos cuidados com ele, procurando uma vaga para estacioná-lo por exemplo, será dedicado ao desempenho de outras atividades.

Algumas inovações relacionadas a rodovias inteligentes alteram o statu quo do que a sociedade entende por privacidade ou geram dúvidas com respeito às responsabilidades envolvidas. Estes casos precisam gerar discussões profundas e ter políticas específicas criadas permitindo que estas inovações sejam absorvidas pela sociedade da melhor maneira possível.

A realidade do sistema viário brasileiro ainda está muito distante dos países desenvolvidos, mas isso não deve eliminar a busca por pesquisas que representam o estado da arte em rodovias inteligentes. Este artigo não avaliou a viabilidade de

\footnotetext{
${ }^{9}$ https://www.faa.gov/uas/

${ }^{10} \mathrm{http}$ //highwaysmagazine.co.uk/drones-to-be-used-for-inspecting-roads/

${ }^{11} \mathrm{http} / /$ www.anac.gov.br/assuntos/paginas-tematicas/drones/regras-de-todos-os-orgaos-brasileiros-sobre-operacaode-drones

${ }^{12} \mathrm{http} / / / g 1$.globo.com/hora1/videos/v/policia-rodoviaria-federal-testa-uso-de-drones-para-fiscalizarestradas/5821493/

iSys: Revista Brasileira de Sistemas de Informação (iSys: Brazilian Journal of Information Systems) http://seer.unirio.br/index.php/isys/
} 
implantação das pesquisas mencionadas, o que deve ser feito caso sejam aplicáveis à alguma região brasileira.

A avaliação das rodovias no contexto brasileiro apresenta como crítico o problema da qualidade da infraestrutura destas, que está intimamente relacionada às atividades de manutenção e conservação das vias. Inevitavelmente, no Brasil é preciso focar nas questões clássicas de infraestrutura tais como problemas de pavimento, iluminação, sinalização e otimização nos processos de manutenção e conservação da via. É fundamental prover aos gestores das rodovias o acesso à sistemas de informação, equipamentos e instrumentos de alta tecnologia, buscando assim melhorar a administração desses processos e facilitando a tomada de decisão destes Órgãos.

Dentro do contexto nacional, a busca pela satisfação do usuário nas rodovias existentes deveria ser fator motivador primordial para os órgãos gestores, como é defendido na visão da STA. Muitos dos problemas das vias estão relacionadas a conservação das mesmas e o monitoramento efetivo da qualidade da manutenção realizada pelas entidades responsáveis, sejam elas federais, estaduais ou municipais, pode trazer melhorias significativas. Para isso, é fundamental compreender os processos atuais de manutenção, em rodovias públicas e concessionadas, para desenvolver sistemas capazes de auxiliar a vistoria dos serviços efetuados e de identificar a causa raiz de problemas recorrentes buscando assim construir soluções efetivas que diminuam a variação na qualidade observada pelo usuário das rodovias brasileiras. Portanto, quando se aumenta o investimento em tecnologias visando a gestão da infraestrutura rodoviária certamente se estará maximizando a qualidade do serviço, da investigação das razões da degradação da Infraestrutura, do acompanhamento das métricas, facilitando alcançar os resultados das atividades de conservação e manutenção esperados.

Com base nesta problemática, o trabalho vinculado a este artigo visa desenvolver solução mobile sensing, que dentre as tecnologias pesquisadas é a que mais contribui para trazer soluções ao problema por possibilitar uma caracterização do ambiente rodoviário no que tange a sua infraestrutura com uma ampla cobertura, além do fato de ser de fácil aplicação dentro da realidade brasileira. O objetivo é melhorar a gestão da manutenção e conservação das rodovias através do uso dos sensores dos smartphones dos agentes da autoridade de trânsito rodoviários e também dos usuários da via. Para isso processos, sistemas, dados existentes e oportunidades de colaboração e comunicação com os usuários da rodovia estão em análise. Nesta pesquisa espera-se contribuir para uma gestão mais efetiva das atividades de manutenção e conservação da infraestrutura rodoviária propiciando um aumento da qualidade e, desta forma, representar um passo na direção das rodovias inteligentes brasileiras.

\section{Referências}

Al-Radaideh A., Al-Ali A. R., Bheiry S. e Alawnah S. (2015). "A Wireless Sensor Network Monitoring System for Highway Bridges", IEEE International Conference on Electrical and Information Technologies (ICEIT). [GS Search] 
ANTT (2014), Agência Nacional de Transportes Terrestre. Pesquisa de satisfação dos usuários.

Disponível

em: http://www.antt.gov.br/textogeral/Pesquisa de Satisfacao dos Usuarios Transport Users_Satisfaction_Survey.html. Acessado em 27/07/2017.

ANTT (2017), Agência Nacional de Transportes Terrestre. Cronograma de instalação de tag eletrônica. http://antt.gov.br/salaImprensa/noticias/arquivos/2017/07/ANTT_publica_cronogram a_de instalacao da identificacao_eletronica_em_veiculos de carga.html. Acessado em 27/07/2017.

Applin, S. A. (2016). "Deliveries by Drone: Obstacles and Sociability". The Future of Drone Use - Opportunities and Threats from Ethical and Legal Perspectives, pp 7192. Editor Bart Custers, Springer. [GS Search]

Auer A., Feese S. e Lockwood S. (2016). "History of Intelligent Transportation Systems", U.S. Department of Transportation, report nr. FHWA-JPO-16-329, Whashigton, https://www.its.dot.gov/history/. Acessado em 27/07/2017.

CNT (2016), Confederação Nacional de Transportes. Pesquisa CNT de Rodovias 2016. Brasília, 2016. Relatório Gerencial n. xx. Disponível em: http://pesquisarodovias.cnt.org.br. Acesso em: 01/10/ 2017.

Cunha F., Villas L., Boukerche A., Maia G., Viana A., Mini R. A. F. e Loureiro A. A. F. (2016). "Data communication in VANETs: Protocols, applications and challenges", Ad Hoc Networks, Vol. 44, pp 90-103. [GS Search]

Custers, B. (2016). "Drones Here, There and Everywhere Introduction and Overview". The Future of Drone Use - Opportunities and Threats from Ethical and Legal Perspectives, pp 3-20. Editor Bart Custers, Springer. [GS Search]

DNIT (2015). Veículo de Diagnóstico de Rodovias, http://www.dnit.gov.br/download/veiculo-de-diagnostico-de-rodovias.pdf. Acessado em 27/07/2017.

DNITa (2017). Departamento Nacional de Infraestrutura de Transportes, http://www.dnit.gov.br/acesso-a-informacao/insitucional. Acessado em 27/07/2017.

DNITb (2017). Índice de Condição da Manutenção - ICM, https://www.dnit.gov.br/icm1/indice-de-condicao-da-manutencao-2013-icm. Acessado em 01/10/2017.

DNITc (2017). Publicação IPR 700. Glossário de Termos Técnicos Rodoviários. IPRInstituto de Pesquisas Rodoviárias, Rio de Janeiro, http://ipr.dnit.gov.br/noticias/novasnormas-em-consulta-publica/MinutaGlossrioTermosTcnicos def.pdf. Acessado em 27/07/2017.

EC (2011), European Commission. European Strategies White Paper 2011. Disponível em: $\quad$ https://ec.europa.eu/transport/themes/strategies/2011_white_paper_en. Acessado em 01/10/2017.

EC (2017), European Commission. The themes of the Road Transport Strategy. Disponível em: https://ec.europa.eu/transport/modes/road/road-initiatives en. Acessado em 01/10/2017. 
EPA (2014), Environment Protection Agency. Inventory of U.S. Greenhouse Gas Emissions and Sinks: 1190 - 2014, https://www.epa.gov/ghgemissions/inventory-usgreenhouse-gas-emissions-and-sinks-1990-2015. Acessado em 27/07/2017.

ETSI (2012), European Telecommunications Standards Institute. DSRC \& Electronic Fee Collection, http://www.etsi.org/technologies-clusters/technologies/automotiveintelligent-transport/dsrc-electronic-feecollection?highlight=YToxOntpOjA7czo0OiJvYnVzIjt9. Acessado em 27/07/2017.

FHWA (1998), Federal Highway Administration. ITS Probe Vehicle Techniques. Disponível em: https://www.fhwa.dot.gov/ohim/handbook/chap5.pdf. Acessado em 01/10/2017.

Ibnkahla M. (2012). Wireless Sensor Networks: A Cognitive Perspective, pp 101-137. CRC Press. [GS Search]

LABTRANS (2015). Transportation and Logistics Laboratory, UFSC. Acessado em 10/06/2017: http://www.labtrans.ufsc.br/media/43794/piaf presentation_final_2.pdf

Li L., Zhang H., Zhao C. e Ding X. (2014). "Radiation Fog Detection and Warning System of Highway Based on Wireless Sensor Networks," IEEE 7th Joint International Information Technology and Artificial Intelligence Conference. [GS Search]

Lira E. R. (2016). TSMA: Uma arquitetura para gerenciar sinalização de trânsito. 88 pp. Dissertação (Mestrado em Ciência da Computação), Universidade Federal de Uberlândia, Uberlândia. [GS Search]

Menouar H., Güvenc I., Akkaya K., Uluagac A. S., Kadri A., e Tuncer A. (2017). "UAV-Enabled Intelligent Transportation Systems for the Smart City: Applications and Challenges", IEEE Magazine, Volume 55, Issue 3, pag. 22-28. [GS Search]

MTPAa (2015), Ministério dos Transportes, Portos e Aviação Civil. Transporte Rodoviário, http://www.transportes.gov.br/transporte-rodoviario-relevancia.html

MTPAb (2017), Ministério dos Transportes, Portos e Aviação Civil. Caderno de Transportes 2015 , http://www.transportes.gov.br/images/2016/05/Transportes2015Versao_Web.pdf.

Neto E., Rentes A. C., Romão V. e Spricigo V. (2016) Rodovias Inteligentes: Contextualização, Simulação e Adequação do Projeto Geométrico. Projeto de Conclusão de curso de Engenharia Civil. 171 pp. Escola Politécnica da Universidade de São Paulo.

Pereira, V. B. (2015). Transportes História, crises e caminhos. Editora Civilização Brasileira.

Picone M., Busanelli S., Amoretti M., Zanichelli F. e Ferrari G. (2015). Advanced Technologies for Intelligent Transportation Systems, Intelligent Systems Reference Library, Vol. 139. Springer. [GS Search]

Shaohan H., S. Hengchang L. L., Hongyan W. e Abdelzaher T. F. (2015). "SmartRoad: Smartphone-Based Crowd Sensing for Traffic Regulator Detection and 
Identification", ACM Transactions on Sensor Networks, Vol. 11, Issue 4, Article 55. [GS Search]

Sato M., Tsukada M., Ito H. (2016). "Probe Vehicle Information Systems", Intelligent Transportation System: From Good Practices to Standards, pp 151-171. Ed. Paolo Pagano, CRC Press.

Senna, L. A. S. (2014). Economia e Planejamento dos Transportes, Elsevier Editora Ltda. [GS Search]

STAa (2015), Smart Transportation Alliance. "Smart Roads: A Vision", http://smarttransportation.org/wp-content/uploads/2015/01/STA_DP_1 2015 Def.pdf.

STAb (2015), Smart Transportation Alliance. "A Strategic Road Research Agenda 2015-2025", http://smart-transportation.org/wpcontent/uploads/2015/01/STA TR 22015 Def.pdf.

Sommerville I. (2011). Software Engineering, 9a Edição. Pearson.

Tientrakool P., Ho Y. e Maxemchuk N. F. (2011), "Highway Capacity Benefits from Using Vehicle-to-Vehicle Communication and Sensors for Collision Avoidance", IEEE, Vehicular Technology Conference (VTC Fall). [GS Search]

Ullah K. (2016). On the use of opportunistic vehicular communication for roadside services advertisement and discovery. $106 \mathrm{pp}$. Tese (Doutorado em Ciencia da Computação e Matemática Computacional), USP, São Carlos. [GS Search]

USDOTa (2017), United States Department of Transportation. Intelligent Transportation System Joint Program Office - How ITS Technology has improved our quality of life. Disponível em: https://www.its.dot.gov/resources/fastfacts.htm. Acessado em: 01/10/2017.

USDOTb (2017), United States Department of Transportation. Sustainable Highways Initiative. Disponível em: https://www.sustainablehighways.dot.gov. Acessado em: $01 / 10 / 2017$.

Vergouw B., Nagel H., Bondt G. e Custers B. (2016). "Drone Technology: Types, Payloads, Applications, Frequency Spectrum Issues and Future Developments". The Future of Drone Use - Opportunities and Threats from Ethical and Legal Perspectives, pp $21-45$. [GS Search]

WHO (2015), World Health Organization. Global Status Report on Road Safety, http://www.who.int/violence injury prevention/road_safety_status/2015/en/.

Yi C., Chuang Y. e Nian C. (2015). "Toward Crowdsourcing-Based Road Pavement Monitoring by Mobile Sensing Technologies", IEEE Transactions on Intelligent Transportation Systems, Vol. 16, No. 4, pp 1905-1917. [GS Search] 